\title{
STATISTICAL ANALYSIS OF FINANCIAL AND ECONOMIC CONDITION IN COMPANIES LISTED ON THE WARSAW STOCK EXCHANGE
}

\author{
Małgorzata Łuniewska, Ph.D. \\ Department of Insurance and Capital Markets \\ Faculty of Economics and Management \\ University of Szczecin \\ Mickiewicza 64, 71-101 Szczecin \\ e-mail: gmentel@prz.edu.pl
}

Received 21 October 2008, Accepted 25 November 2008

\begin{abstract}
The analysis of securities is an essential element of investment. It is a complex and, very frequently, long-lasting process. Depending on the assumed time perspective of an investment, the analysis may be carried out on the basis of appropriate tools within technical or fundamental analysis. Assuming that the investment is long-term, the methods of fundamental analysis, particularly the indicator analysis are be useful. Additionally, in securities analyses taxonomic methods are more frequently used, which allows for the evaluation of the securities quality through the synthetic analysis of statistical economic and financial indicators. Methods of linear arrangement used to assess the companies' fundamental strength are based on the economic and financial indicators. These indicators define in a numerical manner the relations between economic and financial values, which allows for conclusions on the condition of the examined economic entities, sectors or markets. Furthermore, indicators are a source of data in quantitative analyses, they are diagnostic variables in research studies. Thus this situation poses a few crucial questions:

- how do the economic and financial indicators rule on the stock market?

- what is their level, do they maintain the norms ?

- what is the quality of data on the basis of which securities analyses are carried out?

The main goal of the article is to analyze the fundamental power of companies listed on Warsaw Stock Exchange (WSE) by using TMAI value (in space and time). The study was performed in the period of 2005-2008 (the first quarter of 2008). Thus, the base was constituted by 126 companies. Banks and other financial institutions were excluded. Within the macrosectors existing on the Polish capital market, a statistical analysis of the level of economic and financial indicators characterizing particular companies was performed.
\end{abstract}

Key words: investment, analysis of securities, fundamental analysis, sector analysis indicator analysis, synthetic measure of development, numerical methods, statistical analysis.

JEL classification: $\mathrm{C} 10, \mathrm{G} 10$. 


\section{Introduction}

The analysis of securities is an essential element of an investment. It is a complex and, very frequently, long-lasting process. Depending on the assumed time perspective of the investment, the analysis may be carried out on the basis of appropriate tools within technical or fundamental analysis. Assuming that the investment is long-term, the methods of fundamental analysis, particularly the indicator analysis are be useful. Additionally, in securities analyses taxonomic methods are more frequently used, which allows for the evaluation of the securities quality through the synthetic analysis of statistical economic and financial indicators. The combination of elements of the fundamental analysis with statistical, multidimensional methods may be presented in the following manner:

- the study of the companies' fundamental strength, in other words the attractiveness of securities, through the prism of a synthetic combination of economic and financial indicators as an element of the analysis of securities;

- the use of economic and financial indicators as diagnostic variables in multidimensional analyses (e.g. to construct data bases and ways of their utilization in portfolio analyses);

- the study of levels of economic and financial indicators enabling the assessment of the stock companies' level of development, and indirectly, the assessment of the development of the capital market in Poland.

It is essential, however, to examine the quality of data being used to create synthetic measures. Thus, alongside this examination, the fundamental strength or the economic and financial potential of the companies are evaluated. These expectations may be fulfilled thanks to quantitative methods.

The problem of data quality, actually their evaluation, may be carried out with the help of statistical analysis, particularly of the parameters of descriptive statistics. Such a manner of tackling the problem allows for not only explaining the value of synthetic measures, but also for showing the level reach of certain indicators for companies (e.g. on the market or in sectors). In this scope, comparisons both in time and space are correct. Moreover, statistical studies may lead to the search and definition of standard values for the market, sector or group of companies. They indicate and confirm at the same time the disproportions in the levels of economic and financial indicators and development of companies. Both these 
elements influence the evaluation of the companies' fundamental strength and, at the same time, the evaluation of the economic and financial potential they have at their disposal.

Methods of linear arrangement, mainly the synthetic measures of development ${ }^{1}$, enable the classification of companies (entities) in relation to the set variables and by the use of one synthetic dimension they define their fundamental strength. Thus, on the one hand, the level of synthetic measures reflects the economic and financial condition of the examined companies and, indirectly, gives evidence about the capital market development level in Poland. On this basis, one can also make an evaluation of the economic and financial potential the studied companies are vested with. Methods of linear arrangement used to assess the companies' fundamental strength are based on the economic and financial indicators. These indicators define in a numerical manner the relations between economic and financial values, which allows for conclusions on the condition of the examined economic entities, sectors or markets. Furthermore, the indicators are a source of data in quantitative analyses, they are diagnostic variables in research studies. Their value directly influences the level of synthetic measures or the quality of classification. Therefore, there arises an essential problem connected with the quality of statistical data used as a basis for analyses. From the studies carried out for the Polish market with the use of linear arrangement measures it can be seen that the level of synthetic measures for companies classified as good (potentially attractive in terms of investment and fundamentally strong) oscillates most often between values 0.3-0.5. It has to be stressed that in measures based on the synthetic measure of development, normalized within the limits between 0 and 1, the entities (companies) regarded as those having a good level of development are those for which the level of synthetic measure is the highest. This situation poses, then, a few crucial questions:

- how do the economic and financial indicators rule on the stock market?

- what is their level, do they maintain the norms?

- what is the quality of data on the basis of which securities analyses are carried out?

\section{Empirical Research}

The main goal of the article is the analysis of fundamental power of the companies listed on Warsaw Stock Exchange (WSE) by using TMAI value (in space and time). The study was performed in the period of 2005-2008 (the first quarter of 2008), but in all the analyses only full data were used. Companies which entered the market after 2005 were excluded from 
the analysis. Thus, the base was constituted by 126 companies. Banks and other financial institutions were excluded as well.

Within the macrosectors existing on the Polish capital market, a statistical analysis of the level of economic and financial indicators characterizing particular companies was performed. In the statistical study classic and positional mean values ${ }^{2}$ were calculated together with the corresponding measures of volatility and variability ( $\bar{x}-$ mean, $M-$ median, $S(x)$ - standard deviation, $V_{S}$ - classical variability coefficient).

Companies are divided into three macrosectors: industry $(M I)-(70$ companies $)$, trade and services (MTS) - (56 companies), finances and insurance (15 companies). Additionally, for the selected macrosectors and economic and financial indicators that define them, the levels of synthetic measures were set with the help of $T M A I^{3}$.

For the methods chosen for the analysis, the set of diagnostic characteristics comprises:

- profitability indicators: return on equity $(R O E)$, return on assets $(R O A)$,

- liquidity indicator: current ratio $(W P B)$,

- activity indicators: receivables turnover ratio $(R N)$, inventory turnover ratio $(R Z)$, payables turnover ratio $(R Z o b)$, asset turnover ratio $(R A)$,

- debt indicator: debt ratio $(S t Z d)$.

Out of the selected variables ${ }^{4}$, the receivables turnover ratio, inventory turnover ratio and payables turnover ratio, as well as the debt ratio have been treated as destimulants. The current ratio for non-financial companies is the nominat, and the remaining variables have been regarded as stimulants. These variables are commonly available and published, e.g. by Notoria Serwis in quarterly and annual configurations for all companies, which means that the analyses proposed in the article should not pose a problem as for the availability of data.

The results of the analysis have been presented in Tables 1 to 6 in Annex. The conclusion from the analysis of the data presented in Tables 1,2 and 3 is that the average level of synthetic measures oscillates within the range from 0.1 to 0.5 . This proves rather low level of development in the analyzed companies. Considering the fact that these are stock companies, the news sounds even less optimistic. The stock exchange is often described as the economy barometer, and looking through the prism of stock companies analysis, we may discuss the state of the economic situation. Unfortunately, in this field the situation is not good. While analyzing the levels of statistical parameters of mutability and variability, among 
the analyzed companies disproportions can be seen not only with a view to synthetic values, but also to the economic and financial indicators which constitute these measures (Tables 4, 5 and 6). In particular, this is indicated by the classic variability indicators $V_{S}$, which are significantly higher than the statistically acceptable range of small variability $(0-10 \%)$.

The level of synthetic measure enables defining the companies' (or a company's) fundamental strength. In relation to that, at low values of the TMAI (and as the study shows, they are such on average), we may speak of existing, but not yet used economic potential in stock companies. With regard to the market situation and having considered the fact that the Polish market still finds itself in its development phase, such a thesis seems true. Moreover, Tables 1, 2 and 3 also show what the state of the economic development is in macrosectors and sectors. On average, the highest values were obtained in the industry macrosector. However, doubt is raised by a very high variability $\left(V_{S}\right)$ of synthetic measures. It stems from the large differences between particular economic and financial indicators constituting diagnostic variables. This is even more obvious after analyzing the results shown in Tables 46 , which present chosen statistical parameters of economic and financial indicators in the period of 2005-2008, for macrosectors, sectors and all analyzed companies as total.

In this domain, again a high variability of values of indicators obtained by companies has been confirmed, which proves that certain companies are characterized by a very good economic and financial condition, while others - by a very weak one. Such a thesis is correct for all analyzed sub-groups. Generally, it has to be stated that stock companies are struggling with economic and financial problems. Evaluating their economic potential it may be said that there is still a lot to be done in this field. First, the condition of companies needs to be improved in a way that would enable its appropriate use for the aim of improving the economic situation of the sector, macrosector and, thus, the market as a whole.

\section{Conclusions}

The research that has been carried out shows the disproportions on the level of the studied economic and financial indicators, which confirms the differences between certain macrosectors, i.e. between companies that form them (the character of company activity in sectors, the level of their development) and the whole market. The tide of the market is not good, but we may observe certain growth tendencies.

After having done the research, we can see that the presented division into macrosectors on the Polish capital market is not perfect. The sectors are too diversified as for 
number, which may cause analytical difficulties. Despite the shortcomings of the division, the analyses of this kind should be performed due to their applicability in the analyses of securities, the possibility they offer to evaluate the market and its sectors, including the companies as their components. 


\section{APPENDIX}

Table 1. Statistical characteristics of TMAI for WSE companies in 2005-2008

\begin{tabular}{|c|c|c|c|c|c|}
\hline & years & $\bar{x}$ & $M$ & $S(x)$ & $V s$ \\
\hline \multirow{4}{*}{$T M A I A C^{5}$} & 2005 & 0.4591 & 0.4728 & 0.0903 & 0.1966 \\
\hline & 2006 & 0.3203 & 0.3263 & 0.0809 & 0.2525 \\
\hline & 2007 & 0.3681 & 0.3732 & 0.0977 & 0.2655 \\
\hline & 2008 & 0.3428 & 0.3532 & 0.0850 & 0.2480 \\
\hline \multirow{4}{*}{ TMAI MTS } & 2005 & 0.4805 & 0.5036 & 0.1182 & 0.2461 \\
\hline & 2006 & 0.3442 & 0.3450 & 0.0992 & 0.2881 \\
\hline & 2007 & 0.4160 & 0.4339 & 0.1221 & 0.2935 \\
\hline & 2008 & 0.3547 & 0.3694 & 0.1054 & 0.2971 \\
\hline \multirow{4}{*}{ TMAI MI } & 2005 & 0.3945 & 0.4173 & 0.1209 & 0.3064 \\
\hline & 2006 & 0.3423 & 0.3576 & 0.0922 & 0.2694 \\
\hline & 2007 & 0.2976 & 0.2989 & 0.0833 & 0.2799 \\
\hline & 2008 & 0.3598 & 0.3617 & 0.0880 & 0.2445 \\
\hline
\end{tabular}

Source: own calculations.

Table 2. Statistical characteristic of TMAI MI for WSE companies in 2005-2008

\begin{tabular}{|c|c|c|c|c|c|}
\hline TMAI's for sectors & years & $\bar{x}$ & $M$ & $S(x)$ & $V S$ \\
\hline \multirow{4}{*}{ TMAI OTHER } & 2005 & 0.3365 & 0.4036 & 0.2037 & 0.6054 \\
\hline & 2006 & 0.3167 & 0.3438 & 0.1928 & 0.6088 \\
\hline & 2007 & 0.3829 & 0.4243 & 0.1093 & 0.2853 \\
\hline & 2008 & 0.3538 & 0.3758 & 0.0965 & 0.2727 \\
\hline \multirow{4}{*}{ TMAI FOOD } & 2005 & 0.2533 & 0.2612 & 0.1537 & 0.6070 \\
\hline & 2006 & 0.2401 & 0.2383 & 0.1393 & 0.5803 \\
\hline & 2007 & 0.1775 & 0.2102 & 0.1259 & 0.7094 \\
\hline & 2008 & 0.0987 & 0.0782 & 0.0924 & 0.9370 \\
\hline \multirow{4}{*}{ TMAI METALS } & 2005 & 0.2885 & 0.2691 & 0.1495 & 0.5181 \\
\hline & 2006 & 0.2146 & 0.2301 & 0.1619 & 0.7542 \\
\hline & 2007 & 0.2093 & 0.1454 & 0.1776 & 0.8487 \\
\hline & 2008 & 0.2484 & 0.2325 & 0.1567 & 0.6307 \\
\hline \multirow{4}{*}{$\begin{array}{c}\text { TMAI } \\
\text { BUILDING MATERIALS }\end{array}$} & 2005 & 0.2331 & 0.2556 & 0.1197 & 0.5133 \\
\hline & 2006 & 0.1155 & 0.1079 & 0.0827 & 0.7160 \\
\hline & 2007 & 0.1579 & 0.1564 & 0.1569 & 0.9940 \\
\hline & 2008 & 0.2826 & 0.3177 & 0.1550 & 0.5484 \\
\hline \multirow{4}{*}{$\begin{array}{c}\text { TMAI } \\
\text { LIGHT INDUSTRY }\end{array}$} & 2005 & 0.3817 & 0.4363 & 0.1942 & 0.5088 \\
\hline & 2006 & 0.4472 & 0.4638 & 0.2548 & 0.5697 \\
\hline & 2007 & 0.3856 & 0.3898 & 0.2044 & 0.5302 \\
\hline & 2008 & 0.4042 & 0.4347 & 0.1529 & 0.3782 \\
\hline \multirow{4}{*}{$\begin{array}{c}\text { TMAI } \\
\text { ELECTROENGINEERING }\end{array}$} & 2005 & 0.2801 & 0.2829 & 0.1549 & 0.5530 \\
\hline & 2006 & 0.2347 & 0.1859 & 0.1793 & 0.7641 \\
\hline & 2007 & 0.2548 & 0.2315 & 0.1302 & 0.5108 \\
\hline & 2008 & 0.2922 & 0.2598 & 0.1371 & 0.4691 \\
\hline \multirow{4}{*}{$\begin{array}{l}\text { TMAI WOOD } \\
\text { AND PAPER }\end{array}$} & 2005 & 0.3133 & 0.3107 & 0.2196 & 0.7009 \\
\hline & 2006 & 0.3836 & 0.4061 & 0.2183 & 0.5691 \\
\hline & 2007 & 0.3028 & 0.3261 & 0.1548 & 0.5112 \\
\hline & 2008 & 0.2654 & 0.2189 & 0.1307 & 0.4926 \\
\hline \multirow{4}{*}{$\begin{array}{c}\text { TMAI } \\
\text { CHEMISTRY }\end{array}$} & 2005 & 0.2854 & 0.3608 & 0.1413 & 0.4953 \\
\hline & 2006 & 0.2992 & 0.3452 & 0.1407 & 0.4702 \\
\hline & 2007 & 0.2631 & 0.2953 & 0.1383 & 0.5255 \\
\hline & 2008 & 0.3251 & 0.3656 & 0.1456 & 0.4478 \\
\hline
\end{tabular}

Source: own calculations. 
Table 3. Statistical characteristic of TMAI MTS for WSE companies in 2005-2008

\begin{tabular}{|c|c|c|c|c|c|}
\hline & years & $\bar{x}$ & $\mathrm{M}$ & $\mathrm{S}(\mathrm{x})$ & $\mathrm{Vs}$ \\
\hline \multirow{4}{*}{ TMAI MEDIA } & 2005 & 0.3410 & 0.3999 & 0.1963 & 0.5757 \\
\cline { 2 - 6 } & 2006 & 0.3292 & 0.3343 & 0.1781 & 0.5410 \\
\cline { 2 - 6 } & 2007 & 0.4029 & 0.4876 & 0.1886 & 0.4681 \\
\cline { 2 - 6 } & 2008 & 0.3628 & 0.4236 & 0.1391 & 0.3836 \\
\hline \multirow{4}{*}{ TMAI OTHER } & 2005 & 0.4020 & 0.4364 & 0.1665 & 0.4142 \\
\cline { 2 - 6 } & 2006 & 0.1907 & 0.1768 & 0.1365 & 0.7157 \\
\cline { 2 - 6 } & 2007 & 0.2585 & 0.2441 & 0.1952 & 0.7551 \\
\cline { 2 - 6 } & 2008 & 0.2716 & 0.2990 & 0.1720 & 0.6331 \\
\hline \multirow{3}{*}{ TMAI } & 2005 & 0.1901 & 0.1620 & 0.1472 & 0.7742 \\
\cline { 2 - 6 } IT & 2006 & 0.2551 & 0.2297 & 0.1749 & 0.6858 \\
\cline { 2 - 6 } & 2007 & 0.2253 & 0.2616 & 0.1419 & 0.6298 \\
\cline { 2 - 6 } & 2008 & 0.2117 & 0.2275 & 0.1428 & 0.6743 \\
\hline \multirow{3}{*}{ RETAILS } & 2005 & 0.1872 & 0.1537 & 0.2155 & 1.1514 \\
\cline { 2 - 6 } & 2006 & 0.2386 & 0.2422 & 0.1547 & 0.6484 \\
\cline { 2 - 6 } & 2007 & 0.2904 & 0.3073 & 0.1670 & 0.5751 \\
\cline { 2 - 6 } & 2008 & 0.2903 & 0.3067 & 0.1824 & 0.6283 \\
\hline \multirow{3}{*}{ TMAI } & 2005 & 0.1708 & 0.1769 & 0.1122 & 0.6570 \\
\cline { 2 - 6 } & 2006 & 0.1239 & 0.0868 & 0.1077 & 0.8688 \\
\cline { 2 - 6 } & 2007 & 0.2035 & 0.1859 & 0.1238 & 0.6084 \\
\cline { 2 - 6 } & 2008 & 0.2311 & 0.2555 & 0.1408 & 0.6095 \\
\hline \multirow{3}{*}{ TMAI } & 2005 & 0.3672 & 0.4225 & 0.1532 & 0.4172 \\
\cline { 2 - 6 } & 2006 & 0.3885 & 0.4090 & 0.1554 & 0.3999 \\
\cline { 2 - 6 } & 2007 & 0.2352 & 0.2626 & 0.1201 & 0.5105 \\
\cline { 2 - 6 } & 2008 & 0.3069 & 0.3333 & 0.1350 & 0.4398 \\
\hline
\end{tabular}

Source: own calculations.

Table 4. Statistical measures of economic and financial indicators for all companies in $2005-2008$

\begin{tabular}{|c|c|c|c|c|c|}
\hline \multicolumn{2}{|c|}{ Stat. for $A C$} & $\bar{x}$ & $\mathrm{M}$ & $\mathrm{S}(\mathrm{x})$ & $\mathrm{Vs}$ \\
\hline \multirow{4}{*}{$R O E$} & 2005 & 0.093 & 0.101 & 0.199 & 2.131 \\
\cline { 2 - 6 } & 2006 & 0.097 & 0.110 & 0.164 & 1.683 \\
\cline { 2 - 6 } & 2007 & 0.122 & 0.115 & 0.143 & 1.179 \\
\cline { 2 - 6 } & 2008 & 0.117 & 0.099 & 0.138 & 1.184 \\
\hline \multirow{4}{*}{ ROA } & 2005 & 0.059 & 0.046 & 0.080 & 1.360 \\
\cline { 2 - 6 } & 2006 & 0.058 & 0.054 & 0.088 & 1.505 \\
\cline { 2 - 6 } & 2007 & 0.071 & 0.061 & 0.083 & 1.173 \\
\cline { 2 - 6 } & 2008 & 0.067 & 0.056 & 0.082 & 1.234 \\
\hline \multirow{4}{*}{ NPB } & 2005 & 1.915 & 1.625 & 1.078 & 0.563 \\
\cline { 2 - 6 } & 2006 & 1.833 & 1.607 & 1.017 & 0.555 \\
\cline { 2 - 6 } & 2007 & 1.927 & 1.652 & 1.114 & 0.578 \\
\cline { 2 - 6 } & 2008 & 1.812 & 1.635 & 0.950 & 0.524 \\
\hline \multirow{5}{*}{ ZZap } & 2005 & 86.2 & 75.7 & 58.0 & 0.673 \\
\cline { 2 - 6 } & 2006 & 86.0 & 72.1 & 60.0 & 0.698 \\
\cline { 2 - 6 } & 2007 & 91.0 & 75.2 & 70.1 & 0.771 \\
\cline { 2 - 6 } & 2008 & 93.8 & 78.6 & 80.0 & 0.853 \\
\hline & 2005 & 50.9 & 38.4 & 55.4 & 1.089 \\
\cline { 2 - 6 } & 2006 & 50.0 & 38.3 & 55.5 & 1.108 \\
\cline { 2 - 6 } & 2007 & 53.4 & 41.3 & 55.1 & 1.031 \\
\cline { 2 - 6 } & 2008 & 56.3 & 42.2 & 64.0 & 1.136 \\
\hline \multirow{5}{*}{ ZZob } & 2005 & 112.5 & 98.5 & 71.6 & 0.637 \\
\cline { 2 - 6 } & 2006 & 115.7 & 90.7 & 85.4 & 0.738 \\
\cline { 2 - 6 } & 2007 & 124.1 & 99.9 & 77.9 & 0.628 \\
\cline { 2 - 6 } & 2008 & 126.9 & 102.8 & 81.9 & 0.645 \\
\hline
\end{tabular}




\begin{tabular}{|c|c|c|c|c|c|}
\hline \multirow{4}{*}{$R A$} & 2005 & 382.4 & 298.5 & 285.9 & 0.748 \\
\cline { 2 - 6 } & 2006 & 396.3 & 292.4 & 326.7 & 0.824 \\
\cline { 2 - 6 } & 2007 & 453.5 & 339.7 & 370.9 & 0.818 \\
\cline { 2 - 6 } & 2008 & 512.4 & 359.3 & 485.9 & 0.948 \\
\hline \multirow{4}{*}{$S Z$} & 2005 & 0.439 & 0.418 & 0.179 & 0.408 \\
\cline { 2 - 6 } & 2006 & 0.441 & 0.443 & 0.171 & 0.388 \\
\cline { 2 - 6 } & 2007 & 0.410 & 0.400 & 0.174 & 0.425 \\
\cline { 2 - 6 } & 2008 & 0.411 & 0.384 & 0.166 & 0.403 \\
\hline
\end{tabular}

Source: own calculations.

Table 5. Statistic measures of economic and financial indicators for the macrosector of trade and services in 2005-2008

\begin{tabular}{|c|c|c|c|c|c|}
\hline \multicolumn{2}{|c|}{ Stat. for MHU } & $\bar{x}$ & M & $\mathrm{S}(\mathrm{x})$ & Vs \\
\hline \multirow{4}{*}{$R O E$} & 2005 & 0.091 & 0.100 & 0.257 & 2.813 \\
\hline & 2006 & 0.104 & 0.113 & 0.152 & 1.461 \\
\hline & 2007 & 0.134 & 0.135 & 0.110 & 0.819 \\
\hline & 2008 & 0.124 & 0.108 & 0.107 & 0.861 \\
\hline \multirow{4}{*}{$R O A$} & 2005 & 0.054 & 0.041 & 0.077 & 1.431 \\
\hline & 2006 & 0.054 & 0.049 & 0.076 & 1.400 \\
\hline & 2007 & 0.070 & 0.068 & 0.067 & 0.961 \\
\hline & 2008 & 0.065 & 0.056 & 0.063 & 0.969 \\
\hline \multirow{4}{*}{$W P B$} & 2005 & 1.845 & 1.539 & 1.003 & 0.544 \\
\hline & 2006 & 1.631 & 1.586 & 0.699 & 0.428 \\
\hline & 2007 & 1.928 & 1.667 & 1.109 & 0.575 \\
\hline & 2008 & 1.821 & 1.671 & 0.927 & 0.509 \\
\hline \multirow{4}{*}{$R N$} & 2005 & 95.8 & 76.0 & 78.3 & 0.818 \\
\hline & 2006 & 95.6 & 81.4 & 79.8 & 0.834 \\
\hline & 2007 & 101.2 & 70.1 & 90.7 & 0.896 \\
\hline & 2008 & 102.1 & 76.9 & 105.6 & 1.034 \\
\hline \multirow{4}{*}{ RZap } & 2005 & 46.1 & 24.7 & 73.6 & 1.597 \\
\hline & 2006 & 44.9 & 26.4 & 74.8 & 1.666 \\
\hline & 2007 & 48.9 & 30.0 & 73.0 & 1.493 \\
\hline & 2008 & 53.2 & 31.8 & 87.1 & 1.637 \\
\hline \multirow{4}{*}{$R Z o b$} & 2005 & 119.2 & 101.7 & 85.5 & 0.718 \\
\hline & 2006 & 125.0 & 88.0 & 109.8 & 0.878 \\
\hline & 2007 & 123.3 & 95.3 & 81.7 & 0.662 \\
\hline & 2008 & 124.8 & 98.7 & 80.0 & 0.641 \\
\hline \multirow{4}{*}{$R A$} & 2005 & 421.5 & 254.6 & 394.7 & 0.936 \\
\hline & 2006 & 439.6 & 247.8 & 445.6 & 1.014 \\
\hline & 2007 & 486.7 & 284.5 & 466.1 & 0.958 \\
\hline & 2008 & 539.6 & 300.8 & 612.3 & 1.135 \\
\hline \multirow{4}{*}{$S Z$} & 2005 & 0.481 & 0.466 & 0.193 & 0.402 \\
\hline & 2006 & 0.470 & 0.459 & 0.186 & 0.396 \\
\hline & 2007 & 0.445 & 0.444 & 0.197 & 0.443 \\
\hline & 2008 & 0.446 & 0.428 & 0.183 & 0.410 \\
\hline
\end{tabular}

Source: own calculations.

Table 6. Statistic measures of economic and financial indicators for the macrosector of industry in 2005-2008

\begin{tabular}{|c|c|c|c|c|c|}
\hline \multicolumn{2}{|c|}{ Stat. for MP } & $\bar{x}$ & $\mathrm{M}$ & $\mathrm{S}(\mathrm{x})$ & $\mathrm{Vs}$ \\
\hline \multirow{4}{*}{$R O E$} & 2005 & 0.097 & 0.104 & 0.140 & 1.447 \\
\cline { 2 - 6 } & 2006 & 0.093 & 0.110 & 0.174 & 1.858 \\
\cline { 2 - 6 } & 2007 & 0.113 & 0.111 & 0.165 & 1.459 \\
\cline { 2 - 6 } & 2008 & 0.112 & 0.096 & 0.160 & 1.430 \\
\hline \multirow{2}{*}{$R O A$} & 2005 & 0.064 & 0.057 & 0.082 & 1.286 \\
\cline { 2 - 6 } & 2006 & 0.063 & 0.060 & 0.097 & 1.548 \\
\hline
\end{tabular}




\begin{tabular}{|c|c|c|c|c|c|}
\hline & 2007 & 0.073 & 0.061 & 0.094 & 1.299 \\
\hline & 2008 & 0.068 & 0.057 & 0.095 & 1.398 \\
\hline \multirow{4}{*}{$W P B$} & 2005 & 1.980 & 1.688 & 1.141 & 0.576 \\
\hline & 2006 & 2.001 & 1.686 & 1.193 & 0.596 \\
\hline & 2007 & 1.940 & 1.560 & 1.128 & 0.582 \\
\hline & 2008 & 1.817 & 1.635 & 0.975 & 0.537 \\
\hline \multirow{4}{*}{$R N$} & 2005 & 77.4 & 74.1 & 32.2 & 0.416 \\
\hline & 2006 & 77.1 & 70.4 & 35.5 & 0.460 \\
\hline & 2007 & 81.4 & 75.2 & 46.0 & 0.566 \\
\hline & 2008 & 86.2 & 78.6 & 51.6 & 0.599 \\
\hline \multirow{4}{*}{ RZap } & 2005 & 54.9 & 47.1 & 35.9 & 0.653 \\
\hline & 2006 & 54.3 & 46.0 & 33.9 & 0.625 \\
\hline & 2007 & 57.4 & 49.2 & 35.8 & 0.624 \\
\hline & 2008 & 59.2 & 50.4 & 38.1 & 0.643 \\
\hline \multirow{4}{*}{ RZob } & 2005 & 105.5 & 93.3 & 57.2 & 0.542 \\
\hline & 2006 & 107.0 & 90.7 & 59.0 & 0.552 \\
\hline & 2007 & 122.1 & 103.1 & 72.8 & 0.596 \\
\hline & 2008 & 125.9 & 105.3 & 81.5 & 0.647 \\
\hline \multirow{4}{*}{$R A$} & 2005 & 345.7 & 322.0 & 144.9 & 0.419 \\
\hline & 2006 & 356.2 & 327.5 & 179.2 & 0.503 \\
\hline & 2007 & 419.6 & 349.7 & 269.9 & 0.643 \\
\hline & 2008 & 482.2 & 375.4 & 356.6 & 0.740 \\
\hline \multirow{4}{*}{$S Z$} & 2005 & 0.406 & 0.410 & 0.162 & 0.399 \\
\hline & 2006 & 0.418 & 0.405 & 0.157 & 0.375 \\
\hline & 2007 & 0.384 & 0.381 & 0.152 & 0.395 \\
\hline & 2008 & 0.386 & 0.366 & 0.147 & 0.381 \\
\hline
\end{tabular}

Source: own calculations. 


\section{Notes}

${ }^{1}$ For more information about synthetic measures of development see Grabiński, Wydymus, Zeliaś (1989), Pociecha, Podolec, Sokołowski, Zając (1988).

${ }^{2}$ More information see e.g. Hozer (1996) or Krzysztofiak (1981).

${ }^{3}$ TMAI is Taxonomic Measure Attractiveness of Investment which estimates fundamental power of companies. TMAI is described in detail in e.g. Tarczyński (2002).

${ }^{4}$ Stimulant, destimulant and nominant are the names of variables denoting "positive", "negative" and "variable with norm" when explaining given dependent variable.

${ }^{5}$ TMAI AC - TMAI calculated for all companies.

\section{References}

Grabiński, T., Wydymus, S. \& Zeliaś, A. (1989). Metody taksonomii numerycznej w modelowaniu zjawisk społeczno-gospodarczych. Warszawa: PWN.

Hozer, J. (Ed.). (1996). Opis statystyczny. Szczecin: Uniwersytet Szczeciński.

Krzysztofiak, M. (1981). Statystyka. Warszawa: PWN.

Pociecha, J., Podolec, B., Sokołowski, A. \& Zając, K. (1988). Metody taksonomiczne w badaniach spoteczno-ekonomicznych. PWN: Warszawa.

Tarczyński, W. (2002). Fundamentalny portfel papierów wartościowych. Warszawa: PWE. 